\title{
Socio-economic disparities in mortality due to pandemic influenza in England
}

\author{
Paul D. Rutter • Oliver T. Mytton • \\ Matthew Mak $\cdot$ Liam J. Donaldson
}

Received: 1 September 2011/Revised: 2 December 2011/ Accepted: 16 January 2012/Published online: 2 February 2012

(C) Swiss School of Public Health 2012

\begin{abstract}
Objectives This study examines variations in mortality between socio-economic groups due to the pandemic Influenza (H1N1) 2009 virus in England.

Methods We established a system to identify all deaths related to pandemic (H1N1) 2009 influenza. We collected the postcode of every individual who died, and through this determined the socio-economic deprivation, urban-rural characteristics and region of their residence. Across England, we were therefore able to examine how mortality rates varied by socio-economic group, between urban and rural areas, and between regions.

Results People in the most deprived quintile of England's population had an age and sex-standardised mortality rate three times that experienced by the least deprived quintile $(\mathrm{RR}=3.1,95 \%$ CI 2.2-4.4). Mortality was also higher in urban areas than in rural areas $(\mathrm{RR}=1.7,95 \% \mathrm{CI}$ 1.2-2.3). Mortality rates were similar between regions of the country.

Conclusion Tackling socio-economic health inequalities is a central concept within public health, but has not always been a part of emergency preparedness plans. These data
\end{abstract}

\footnotetext{
P. D. Rutter $(\varangle) \cdot$ L. J. Donaldson Imperial College, London, UK e-mail: p.d.rutter@gmail.com

L. J. Donaldson

e-mail: Liam.donaldson@npsa.nhs.uk

O. T. Mytton

University of Oxford, Oxford, UK

e-mail: olivermytton@dph.ox.ac.uk

M. Mak

King's College Hospital, London, UK

e-mail: Matthew.mak02@imperial.ac.uk
}

demonstrate the opportunity to reduce the overall impact and narrow inequalities by considering socio-economic disparities in future pandemic planning.

Keywords Influenza Pandemic .

Emergency preparedness - Health inequalities .

Socio-economic deprivation

\section{Introduction}

In 1931 Edgar Sydenstricker described the incidence of pandemic influenza by socio-economic class in America (Sydenstricker 2006, reprint). He found a significantly higher incidence amongst the poorest members of society, challenging the then familiar concept that "the flu hit the rich and the poor alike" (Lawrence 2006). The principal risk groups identified from the recent pandemic have been the young, the elderly and those with underlying co-morbidities (Baker et al. 2009; Dominguez-Cherit et al. 2009; Donaldson et al. 2009; Mytton et al. 2011; Sachedina and Donaldson 2010; Webb et al. 2009). More severe illness in certain racial groups has also been reported (Baker et al. 2009; Sachedina and Donaldson 2010). Beyond that, it might be assumed that 'flu affects people randomly.

Disasters strike at random. It might seem reasonable to assume that the rich and poor would be equally affected. But disasters, from the sinking of the Titanic to the Chicago heat-wave and Hurricane Katrina, show a socioeconomic gradient in mortality (Hall 1986; Atkins and Moy 2005; Semenza et al. 1996).

Health inequalities remain a central concept within public health, receiving much attention (Commission on Social Determinants of Health 2008; The Marmot Review 2010). Yet it is unusual for emergency preparedness 
planning to consider health inequalities. There was no explicit reference in the United Kingdom's national framework for preparing for pandemic flu (Department of Health 2007).

We set out to explore disparities between different socio-economic groups in mortality due to pandemic influenza in England. We also sought to explore differences between regions, and between urban and rural areas.

\section{Methods}

We established a system to identify all deaths in England suspected to be related to pandemic (H1N1) 2009 influenza (Donaldson et al. 2009). The system ran until 18 April 2010. A full description of our method, together with results, has been published elsewhere (Donaldson et al. 2009; Mytton et al. 2011; Sachedina and Donaldson 2010). This paper considers the geographic residence of those dying, in terms of: (a) socio-economic deprivation; (b) rural or urban area; and (c) the region of England.

\section{Data collection: deaths}

As part of the standard investigation into each death, a basic set of demographic information was collected. This included the patient's National Health Service (NHS) number and postcode. In the United Kingdom every address has a unique 5-7 digit postcode. There are approximately 1.8 million postcodes. The NHS number is a unique identifier, allocated to individuals at birth or on immigration. Where postcodes were missing we used the NHS number to obtain the patient's postcode. We used postcodes to identify the location in which a patient normally resided (as opposed to where they were treated).

Socio-economic deprivation

The Index of Multiple Deprivation (IMD) is used in England as a means to describe the socio-economic deprivation of an area. It is a pooled score based on measures of income, education, housing, health and crime. For analysis, England is divided into 32,482 distinct geographical units known as LSOAs (lower super-output areas). These have a minimum population of 1,000 and a mean population of 1,500. The 32,482 LSOAs were ranked based on their deprivation score from highest to lowest (where a high score indicates high deprivation). They were then divided into five approximately equal population groups to create quintiles. Each death was allocated to a quintile based on the LSOA in which the patient resided. Deaths were linked to LSOA using the postcode. Age and sex-standardised mortality rates were calculated for each quintile, directly standardised to the English mid-year population estimates for 2009 (Office for National Statistics 2009). Age and comorbidities of those dying were compared across the quintiles.

\section{Urban-rural category}

Each postcode was categorised as urban or rural using the National Statistics Postcode Directory. Each of 165,665 census output areas in England is categorised as urban or rural. Census output areas forming part of a settlement of 10,000 people or more are classified as urban. The remainder of census output areas are classified as rural. Census output areas are co-terminal with postcodes. Age and sex-standardised mortality rates were calculated for urban and rural areas, standardised to the English mid-year population estimates for 2009 .

To better understand the effect of population density and socio-economic deprivation, the urban and rural populations were further stratified into two groups, representing the most deprived two-fifths, and the least deprived threefifths. Age and sex-standardised mortality rates were calculated for these four groups.

\section{Regional data}

Deaths were assigned to one of the ten English regions based on postcode of residence. Mid-2009 population estimates were used to calculate age and sex-standardised mortality rates for each region.

\section{Statistical analysis}

As described above, directly standardised mortality rates were calculated for each sub-group of interest (quintiles of deprivation, urban-rural areas, and regions). Each subgroup was stratified into 15-year sex-specific age bands. Age and sex-specific mortality rates were calculated and applied to mid-2009 population estimates for England (Office for National Statistics 2009) to produce directly standardised mortality rates (Eayres 2008). The 95\% confidence intervals for these directly standardised mortality rates were calculated by an exact method using the Poisson distribution (Dobson et al. 1991). The 95\% confidence intervals for the relative risk between sub-groups were calculated using the standard error of the $\log$ of the rate ratios. Kruskal-Wallis one-way analysis of variance by ranks was used to test for a difference in the median age and number of underlying conditions across the deprivation quintiles. A Chi-squared test was used to compare the proportion with an underlying condition across the deprivation quintiles. Statistical analysis was undertaken in Microsoft Excel 2007 and SPSS version 17. 


\section{Results}

In total, 365 deaths were reported to be due to pandemic influenza in England to 28 March 2010. This analysis includes 349 of these deaths. It excludes 16 deaths where no valid postcode was available. Amongst the included cases, the mean age at death was 42 years $(\mathrm{SD}=23.1)$ and $53 \%$ were male. The majority $(87.3 \%)$ had at least one underlying medical condition.

Socio-economic deprivation

Age and sex-standardised mortality rate increased with increasing deprivation (Table 1). People in the most deprived quintile of England's population suffered an age and sex-standardised mortality rate three times that experienced by the least deprived quintile $(\mathrm{RR}=3.1,95 \%$ CI 2.2-4.4).

The proportion of those who died who had at least one medical condition did not differ significantly between quintile groups $\left(\chi^{2}=2.698, d f=4, p=0.61\right.$; Table 2). The mean number of conditions also did not vary significantly (Kruskal-Wallis, $p=0.07$ ). Amongst those who died, individuals in more deprived quintiles tended to be younger than those in less deprived quintiles (KruskalWallis, $p=0.046$ ).

Urban-rural

The age and sex-standardised mortality rate was higher in urban areas than in rural areas $(\mathrm{RR}=1.7,95 \%$ CI 1.2-2.3; Table 3 ). This difference is seen for both the more deprived

Table 1 Age and sex-standardised mortality rates due to pandemic (H1N1) 2009 influenza in England (1 June 2009-18 April 2010) by quintile of deprivation, analysed at the super output area level

\begin{tabular}{llcll}
\hline Quintile & $\begin{array}{l}\text { Population } \\
\text { (thousands) }\end{array}$ & Deaths & $\begin{array}{l}\text { Mortality rate } \\
\text { (95\% CI) (deaths } \\
\text { per million people) }\end{array}$ & RR (95\% CI) \\
\hline 5 (least deprived) & 10,289 & 42 & $3.9(2.8-5.2)$ & 1 \\
4 & 10,289 & 56 & $5.3(4.0-6.9)$ & $1.4(0.9-2.1)$ \\
3 & 10,289 & 53 & $5.1(3.8-6.7)$ & $1.3(0.9-2.0)$ \\
2 & 10,289 & 80 & $7.8(6.2-9.7)$ & $3.0(1.4-3.0)$ \\
1 (most deprived) & 10,289 & 118 & $12.0(9.9-14.4)$ & $3.1(2.2-4.4)$ \\
\hline
\end{tabular}

Standardised to mid-year 2009 population estimates for England (Office for National Statistics 2009)

Table 2 Characteristics of those who died due to pandemic (H1N1) 2009 influenza in England (1 June 2009-18 April 2010), by quintile of deprivation

Table 3 Age and sexstandardised mortality rates due to pandemic (H1N1) 2009 influenza in England (1 June 2009-18 April 2010) in urban and rural areas

Standardised to mid-year 2009 population estimates for England (Office for National Statistics 2009)

\begin{tabular}{lcclc}
\hline Quintile & Deaths & Mean age & $\begin{array}{l}\text { Mean number } \\
\text { of conditions }\end{array}$ & $\begin{array}{l}\text { Proportion } \\
\text { with at least } \\
\text { one condition }\end{array}$ \\
\hline 5 & 42 & 49.64 & 1.81 & $81 \%$ \\
4 & 56 & 45.91 & 2.41 & $89 \%$ \\
3 & 53 & 43.23 & 2.28 & $85 \%$ \\
2 & 80 & 37.80 & 2.21 & $88 \%$ \\
1 & 118 & 39.86 & 2.55 & $90 \%$ \\
$p$ (Kruskal-Wallis) & & 0.046 & 0.07 & \\
$p$ (Chi-square) & & & & 0.61
\end{tabular}

\begin{tabular}{lcccc}
\hline Area & $\begin{array}{l}\text { Population } \\
\text { (thousands) }\end{array}$ & Deaths & $\begin{array}{l}\text { Mortality rate } \\
(95 \% \text { CI })(\text { deaths } \\
\text { per million people) }\end{array}$ & RR (95\% CI) \\
\hline Rural & 9,798 & 44 & $4.4(3.2-6)$ & 1 \\
Urban & 42,011 & 305 & $7.3(6.5-8.2)$ & $1.7(1.2-2.3)$ \\
\hline Rural, Q1-Q2 & 1,178 & 7 & $6.3(2.5-13)$ & $1.5(0.7-3.4)$ \\
Rural, Q3-Q5 & 8,620 & 37 & $4.2(2.9-5.8)$ & 1 \\
Urban, Q1-Q2 & 19,545 & 191 & $10.1(8.7-11.7)$ & $2.4(1.7-3.5)$ \\
Urban, Q3-Q5 & 22,467 & 114 & $5(4.2-6)$ & $1.2(0.8-1.8)$ \\
\hline
\end{tabular}


Table 4 Age and sexstandardised mortality rates due to pandemic (H1N1) 2009 influenza by region of England (1 June 2009-18 April 2010)
Standardised to mid-year 2009 population estimates for England (Office for National Statistics 2009). National Health Service administrative areas called Strategic Health Authorities

\begin{tabular}{lllll}
\hline Region & $\begin{array}{l}\text { Population } \\
\text { (thousands) }\end{array}$ & Deaths & $\begin{array}{l}\text { Mortality rate } \\
\text { (95\% CI) } \\
\text { (deaths per } \\
\text { million people) }\end{array}$ & RR (95\% CI) \\
\hline East of England & 5728.9 & 27 & $4.7(3.1-6.9)$ & 1 \\
South West & 5215.3 & 30 & $5.6(3.7-8)$ & $1.2(0.7-2)$ \\
South Central & 4071.8 & 23 & $5.6(3.6-8.5)$ & $1.2(0.7-2.1)$ \\
South East Coast & 4305.9 & 28 & $6.5(4.3-9.4)$ & $1.4(0.8-2.3)$ \\
Yorkshire and the Humber & 5210.6 & 34 & $6.5(4.5-9.1)$ & $1.4(0.8-2.3)$ \\
North West & 6908.9 & 47 & $6.8(5-9.1)$ & $1.4(0.9-2.3)$ \\
North East & 2575.4 & 19 & $7.2(4.3-11.3)$ & $1.5(0.8-2.7)$ \\
East Midlands & 4400.8 & 33 & $7.3(5.1-10.3)$ & $1.6(0.9-2.6)$ \\
West Midlands & 5411.9 & 43 & $8(5.8-10.7)$ & $1.7(1-2.7)$ \\
London & 7619.3 & 65 & $9.5(7.3-12.2)$ & $2(1.3-3.1)$ \\
\hline
\end{tabular}

two-fifths of the population (10.1 vs. 6.3 deaths per million, Table 3 ) and the less deprived three-fifths (5.0 vs. 4.2 deaths per million). Similarly, the relationship between deprivation and mortality rate is seen in both rural and urban areas.

\section{Regional}

The age-standardised population mortality rates were similar across most regions (Table 4). The East of England had the lowest rate (4.7 deaths per million, 95\% CI 3.1-6.9). London had the highest rate (9.5 deaths per million, 95\% CI 7.3-12.2), two fold greater than the East of England $(\mathrm{RR}=2.0,95 \% \mathrm{CI} 1.3-3.1)$.

\section{Discussion}

In England, the 2009-2010 influenza pandemic caused significantly greater mortality amongst the most deprived segments of society. To the best of our knowledge, this paper presents the first illustration of such an effect in this first pandemic of the twentieth century. If the lower mortality rate experienced by the richest fifth had applied universally across the population, 148 (i.e. 40\%) fewer people would have died. This significant socio-economic disparity should be addressed when planning for future pandemics and "flu seasons.

We could not determine how the incidence of "flu varied between socio-economic groups. The excess mortality deprivation effect may have been due to a greater incidence of 'flu (Lee et al. 2011), a higher proportion of cases resulting in death, or a combination. Both effects were demonstrated in the 1918 influenza pandemic (Sydenstricker 2006).

A number of factors may account for the observed excess mortality. Chronic diseases are known to be more prevalent amongst the more deprived (Commission on Social Determinants of Health 2008; The Marmot Review 2010). A chronic disease increases an individual's likelihood of dying from pandemic influenza (Baker et al. 2009; Dominguez-Cherit et al. 2009; Donaldson et al. 2009; Mytton et al. 2011; Sachedina and Donaldson 2010; Webb et al. 2009). It is unlikely that the observed threefold mortality difference between the most and least deprived quintiles can be explained purely by differences in the prevalence of underlying risk factors. The precise socioeconomic distribution of influenza risk factors in the English population is unknown. However, studies of important risk conditions such as diabetes and coronary heart disease in England have estimated prevalence to be $50-60 \%$ greater amongst the most deprived quintile than amongst the least deprived quintile (Congdon 2008; Connolly et al. 2000). Whilst a 50-60\% difference is important, it is insufficient to explain the $200 \%$ higher mortality rate that we observed.

Socio-economic deprivation may also result in poorer health because of poorer access to or use of healthcare (Commission on Social Determinants of Health 2008; Coupland et al. 2007; The Marmot Review 2010). The most affluent may have been more likely to seek and use antiviral medication, or to seek a medical opinion early when unwell. Certainly deprivation is a predictor of late presentation for other diseases whose management is time critical (Fraser et al. 2001; Sheifer et al. 2000). A lower uptake of vaccine amongst the most deprived groups may also have contributed. This has previously been observed for the seasonal influenza vaccine (Coupland et al. 2007). The pandemic vaccine only became widely available in November 2009 as the second wave of the pandemic was peaking, so differential vaccine uptake could only have affected deaths that occurred after this time. Other factors beyond the tight remit of health services may be important. Overcrowding, poorer nutrition or reduced awareness of 
public health messages amongst the more deprived might have contributed to a higher incidence of influenza in that group.

Our analysis also demonstrates that mortality was greater in urban than in rural areas. This appears unlikely to be solely explained by greater deprivation in urban areas as the marked socio-economic gradient exists in both urban and rural areas separately. Excess urban mortality might be expected due to higher transmission and incidence of 'flu in more densely populated urban areas (McSweeny et al. 2007). However, access to healthcare is known to be poorer amongst rural populations, which might predict higher mortality in rural areas (Baird 2000; Campbell et al. 2001; Launoy et al. 1992). An urban-rural effect was also observed in the 1918 influenza pandemic. The mortality rate was $30-40 \%$ greater in urban than in rural areas (Chowell et al. 2008).

Regional differences in mortality were slight. London experienced the highest mortality, and the East of England the lowest. The East of England is a mainly rural, largely affluent, part of the country. London is the only region that is entirely urban, with pockets of marked deprivation. These factors could account for the observed regional variation.

Striking differences in the incidence and case fatality of H1N1 (2009) pandemic influenza by age have been previously described (Baker et al. 2009; Dominguez-Cherit et al. 2009; Donaldson et al. 2009). In our study, the mean age of death also varied by socio-economic quintile. Might the higher portion of young people living in the most deprived areas explain our findings? This is unlikely. The mortality rates are age-standardised in 15-year age bands to control for an effect by age. Moreover, it has been shown that, although incidence and case fatality rates varied between age groups, pandemic influenza mortality rates in the population as a whole were similar across age bands (Donaldson et al. 2009). The differences in mean age of death by quintile reflect the different underlying age structures of these groups.

Our finding of an association between deprivation and mortality within a single country may have a parallel at the international level. Charu et al. (2011) compared the pandemic influenza (H1N1) 2009 mortality rate observed in Mexico with that observed in other countries. They found that Mexico experienced a higher mortality rate than was seen in more developed (less deprived) countries.

When Hurricane Katrina struck the Atlantic seaboard in 2005 , the extent to which individuals were affected was highly dependent on their racial and socio-economic group. Examining the different behaviours, often culturally and economically driven, has enabled a fuller appreciation of the reasons behind the observed differences (Elliot and
Race 2006). Likewise, it seems important to more completely understand the root causes of the disparities presented here. This will enable more effective planning of interventions for the next pandemic, the next 'flu season, or the next health disaster. Further research should start by examining whether the higher mortality rate amongst the more deprived was due to a higher incidence of disease, a higher case fatality rate, or a combination of the two. This is important in guiding action. If the explanation lies in higher incidence, the solution needs to involve preventative measures including vaccination. If the explanation lies in higher case fatality, the solution should include measures directed towards those who become unwell, such as ensuring early availability of antiviral medication.

The observed socio-economic differences in mortality raise intriguing questions for policy-makers and planners, balancing population approaches and high-risk approaches (Rose 1985). Although it is beyond the scope of this paper to review the consideration of socio-economic disparities in the previous pandemic plans of every country, it is certainly the case that the United Kingdom plans did not explicitly recognise this issue. The country had detailed plans in place well before the 2009 influenza pandemic began (Department of Health 2007). These recognised the vulnerability of individuals with underlying medical conditions, and considered the potential for a differential impact by age group. But the plans made no mention of more deprived groups being at greater risk. Neither did they foresee a differential impact between rural and urban areas. They set out a communication strategy directed towards the population as a whole, without segmentation by geography or by socio-economic group.

When the pandemic came, targeting vaccination towards those with known risk conditions was a key part of the UK government's response. Should this be extended further? Should those living in the least affluent areas or urban areas be offered immunisation first? Should immunisation be pursued more vigorously in such areas? Many of the key messages were disseminated through a national advertising campaign and through the media. This may not be the most appropriate way to target the right messages at more vulnerable minority groups. A two-pronged approach, delivering both population messages and messages targeted at high-risk groups, could have greater success.

The sharp gradient in mortality rate between the richest and poorest emphasises the imperative of making such considerations a core part of future pandemic planning. There was substantial additional mortality amongst the most vulnerable people in society. Targeted interventions seem to be indicated, and may offer the opportunity to save lives. 


\section{References}

Atkins D, Moy EM (2005) Left behind: the legacy of hurricane Katrina. BMJ 331:916-918

Baird GA (2000) Centralisation of cancer services in rural areas has disadvantages. BMJ 320:717-718

Baker MG, Kelly H, Wilson N (2009) Pandemic H1N1 influenza lessons from the southern hemisphere. Euro Surveill 14(42) (pii:19370)

Campbell NC, Elliott AM, Sharp L, Ritchie LD, Cassidy J, Little J (2001) Rural and urban differences in stage at diagnosis of colorectal and lung cancers. Br J Cancer 84(7):910-914

Charu V, Chowell G, Majia LSF, Echevarria-Zuno S, Borja-Aburto VH, Simonsen L, Miller MA, Viboud C (2011) Mortality burden of the A/H1N1 pandemic in Mexico: a comparison of deaths and years of life lost to seasonal influenza. Clin Infect Dis 53(10):985-993

Chowell G, Bettencourt LMA, Johnson N, Alonso WJ, Viboud C (2008). The 1918-1919 influenza pandemic in England and Wales: spatial patterns in transmissibility and mortality impact. Proc R Soc B 275:501-509

Commission on Social Determinants of Health (2008) CSDH Final Report: closing the gap in a generation: health equity through action on the social determinants of health. World Health Organization, Geneva

Congdon P (2008) Estimating CHD prevalence by small area: integrating information from health surveys and area mortality. Health Place 14:59-75

Connolly V, Unwin N, Sherriff P, Bilous R, Kelly W (2000) Diabetes prevalence and socioeconomic status: a population based study showing increased prevalence of type 2 diabetes mellitus in deprived areas. J Epidemiol Community Health 54:173-177

Coupland C, Harcourt S, Vinogradova Y, Smith G, Joseph C, Pringle M, Hippisley-Cox J (2007) Inequalities in uptake of influenza vaccine by deprivation and risk group: time trends analysis. Vaccine 25(42):7363-7371

Department of Health (2007) Pandemic flu: a national framework for responding to an influenza pandemic. Available at http://www. dh.gov.uk/en/Publicationsandstatistics/Publications/Publications PolicyAndGuidance/DH_080734. accessed 24 Jan 2012

Dobson A, Kuulasmaa K, Eberle E, Scherer J (1991) Confidence intervals for weighted sums of Poisson parameters. Stat Med 10:457-462

Dominguez-Cherit G, Lapinsky SE, Macias AE, Pinto R, EspinosaPerez L, Torre A et al (2009) Critically Ill patients with 2009 influenza $\mathrm{A}(\mathrm{H} 1 \mathrm{~N} 1)$ in Mexico. J Am Med Assoc 302:1880-1887

Donaldson LJ, Rutter PD, Ellis BM, Greaves FEC, Mytton OT, Pebody RG, Yardley IE (2009) Mortality from pandemic A/H1N1 2009 influenza in England: public health surveillance study. BMJ 339:b5213

Eayres D (2008) APHO technical briefing 3: commonly used public health statistics and their confidence intervals. Available at
http://www.apho.org.uk/resource/item.aspx?RID=48457. accessed 1 Dec 2011

Elliot JR, Race Pais J (2006) Class and Hurricane Katrina: social differences in human response to a disaster. Soc Sci Res 35:295-321

Fraser S, Bunce C, Wormald R, Brunner E (2001) Deprivation and late presentation of glaucoma: case-control study. BMJ 322(7287):639-643

Hall W (1986) Social class and survival on the S.S. Titanic. Soc Sci Med 22(6):687-690

Launoy G, Le Coutour X, Gignoux M, Pottier D, Duglex G (1992) Influence of rural environment on diagnosis, treatment, and prognosis of colorectal cancer. J Epidemiol Community Health 46(4):365-367

Lawrence AJ (2006) The incidence of influenza among persons of different economic status during the epidemic of 1918 (1931): commentary. Public Health Rep 121(Suppl 1): 190

Lee BY, Brown ST, Bailey RR, Zimmerman RK, Potter MA et al (2011) The benefits to all of ensuring equal and timely access to influenza vaccines in poor communities. Health Aff 30(6):11411150

McSweeny K, Colman A, Fancourt N, Parnell M, Stantiall S, Rice G, Baker M, Wilson N (2007) Was rurality protective in the 1918 influenza pandemic in New Zealand? NZ Med J 120(1256): U2579

Mytton OT, Rutter PD, Mak M, Stanton EA, Sachedina N, Donaldson LJ (2011) Mortality from pandemic (H1N1) 2009 influenza in England: a comparison of the first and second waves. Epidemiol Infec Nov 1:1-9 (epub)

Office for National Statistics (2009) Population Estimates for UK, England and Wales, Scotland and Northern Ireland, 2009. Available at http://www.ons.gov.uk/ons/publications/re-referencetables.html?edition=tcm\%3A77-213645. accessed 18 Nov 2011

Rose G (1985) Sick individuals and sick populations. Int J Epidemiol 14:32-38

Sachedina N, Donaldson LJ (2010) Paediatric mortality related to pandemic influenza A H1N1 infection in England: an observational population-based study. Lancet 376(9755):1846-1852

Semenza JC, Rubin CH, Falter KH, Selanikio JD, Flanders WD, Howe HL, Wilhelm JL (1996) Heat-related deaths during the July 1995 heat wave in Chicago. N Engl J Med 335:84-90

Sheifer SE, Rathore SS, Gersh BJ, Weinfurt KP, Oetgen WJ, Breall JA, Schulman KA (2000) Time to presentation with acute myocardial infarction in the elderly: associations with race, sex, and socioeconomic characteristics. Circulation 102(14):1651-1656

Sydenstricker E (2006) The incidence of influenza among persons of different economic status during the epidemic of 1918. Public Health Rep 121(Suppl 1):191-204

The Marmot Review (2010) Fair society, healthy lives

Webb SA, ANZIC Influenza Investigators (2009). Critical care services and $2009 \mathrm{H} 1 \mathrm{~N} 1$ influenza in Australia and New Zealand. New Eng J Med 361: 1925-1934 